\title{
LAS MÁQUINAS MAGNETO-ELÉCTRICAS DE GRAMME, EMPLEADAS EN EL ALUMBRADO ELÉCTRICO
}

\author{
Estudio de don Luis L. Zegers
}

\section{SUMARIO}

I.- Orijen de los aparatos magneto-eléctricos. - II. - 1. Máquina de Gramme. -2. Máquina de Gramme empleada en los laboratorios. - 3. Máquina de Gramme sin imanes i carácter especial de las que se emplean en el alumbrado. - 4. Transformación de la electricidad en trabajo. - III. - 1, Arco voltaico. - 2. Regulador Serrin. - 3. Lámpara de mano. - 4. Reflectores i proyectores. - 5. Carbones eléctricos. - 6. Conductores. - IV. - Instalación jeneral; costo del alumbrado eléctrico i reglas relativas al manejo de los aparatos. - V. - 1. Aplicaciones industriales del alumbrado eléctrico. - 2. Alumbrado en los faros. - 3. Alumbrado en los buques. - 4. Aplicaciones militares.

\section{INTRODUCCIÓN}

No es nuestro ánimo hacer un estudio completo sobre las máquinas de Gramme: tal trabajo obligaría a entrar de lleno en la árdua teoría de los aparatos magneto-eléctricos. Nos proponemos solamente reunir metódicamente aquellas indicaciones indispensables para la buena instalación i el fácil manejo de los aparatos de Gramme, actualmente empleados en el alumbrado eléctrico i que se encuentran esparcidas en las muchas publicaciones que sobre esta materia se han dado a luz.

\section{ORÍJEN DE LOS APARATOS MAGNETO-ELÉCTRICOS}

Puede decirse, en un sentido jeneral, que las máquinas magneto-eléctricas, ya sean las destinadas al alumbrado, ya a la galvanoplástica o a otros usos, tienen por objeto principal transformar el trabajo mecánico en electricidad. Se les da el nombre de magneto-eléctricas, porque el magnetismo es la fuente de las corrientes, tanto en los aparatos provistos de imanes, como en los que llevan electro-imanes; i también para distinguir estos aparatos de inducción de las máquinas con platillos de vidrio u otro cuerpo de propiedades eléctricas análogas que transforman igualmente el trabajo en electricidad.

En 1820 Cerstedt notó la desviación que esperimentaba la direccion de una aguja imantada al aproximarla a un circuito eléctrico cerrado. Igual fenómeno se produce 
cuando en vez de un circuito se tiene un iman; i de aquí la analojía entre la electricidad i el magnetismo.

Ampére, ocho días despues de conocer este trascendental esperimento, pudo comprobrar esperimentalmente los resultados que le indicaban el cálculo, mostrando la accion recíproca de dos corrientes, i la de los imanes sobre las corrientes.

Sucedieron a estos trabajos los hermosos esperimentos de Arago, que vinieron a poner de manifiesto que una corriente eléctrica puede desarrollar el magnetismo en un barrote de hierro o acero; i Faraday en 1830 demostró que un iman puede dar lugar a la produccion de una corriente eléctrica.

Las corrientes desarrolladas bajo la influencia de un iman o de un circuito electrizado se llamaron corrientes de induccion o corrientes inducidas. A la barra imantada o a la primera corriente que provoca la produccion de corrientes inducidas, llamóse inductor o corriente inductora.

La primera máquina magneto-eléctrica fue sin duda el sencillo aparato que hizo construir Faraday, para probar que existen corrientes inducidas en un círculo o anillo metálico que jira rápidamente delante de los polos de un iman.

Para realizar los diversos esperimentos de Faraday, Pixii construyó en 1838 una máquina mui injeniosa que aun existe en el laboratorio de física del Colejio de Francia, i de la cual, la mui conocida de Clarke no es sino una variante.

En fin, sucesivamente fueron apareciendo las máquinas debidas a Saxton, Nollent, Siemens, Wheatstone, Ruhmkorff, Wilde i otros: i por último la de Gramme, a la que nos vamos a concretar, empezando por dar una idea acerca de su teoría que ha sido bien espuesta por M. Gaugain, ${ }^{9}$ i por Drion i Fernet en su tratado de física.

\section{MÁQUINA DE GRAMME}

Conviene recordar, ántes de abordar la descripcion de la máquina de Gramme, el mas sencillo de los esperimentos relativos a los fenómenos de induccion magneto-eléctrica.

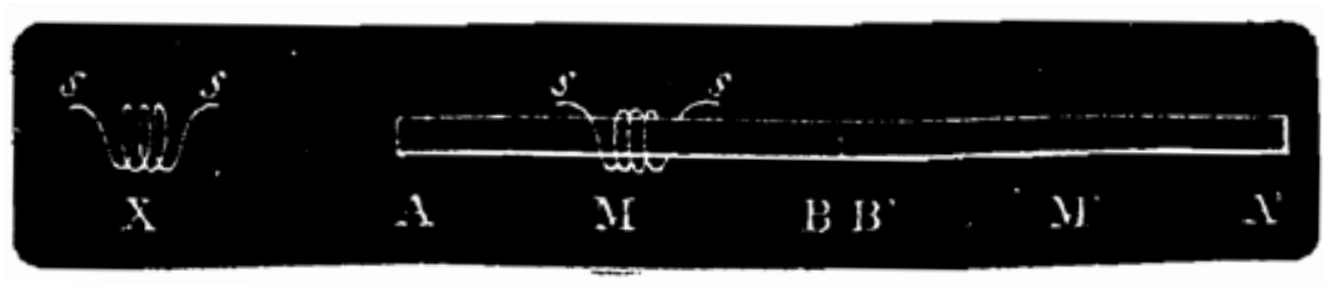

Figura 1

Sean una barra imantada A B (Figura 1) de un metro de largo i una espiral formada con un hilo conductor, animadas ámbas de un movimiento recíproco. Si desde la posición X

9. Annales de Chimie et de Physique, 1873 4e série, t XXVIII. 
acercamos la espiral al iman se produce una corriente de inducción. Esto nos lo dice la lei de Lenz, pero no nos contentemos con comprobar la existencia de la corriente, examinemos también lo que sucede a medida que la barra penetra en la espiral, efectuando una série de movimientos de igual magnitud, de cinco centímetros por ejemplo.

A cada uno de esos movimientos corresponde el desarrollo de una corriente de inducción, i las corrientes así desarrolladas son del mismo sentido hasta el momento en que la espiral llega frente a la línea neutra o mitad M de la barra A B; son de sentido opuesto si el movimiento continúa en el mismo sentido, pero mas allá del punto neutro.

Así, durante el trayecto completo de la espiral sobre el iman, se distinguen dos períodos bien distintos: en la primera mitad del movimiento las corrientes son en sentido directo, en la segunda son en sentido inverso.

Estos fenómenos se han esplicado asimilando el iman a un solenoide.

Si en lugar de mover la espiral de izquierda a derecha, como lo hemos hecho, se la mueve de derecha a izquierda, todo pasa de la misma manera, pero la corriente es en sentido opuesto.

Examinemos ahora el caso complejo representado en la figura 1. Dos imanes A B i B' A' están colocados de manera que se tocan sus extremidades que corresponden a polos del mismo nombre B, B'. El todo aparece como un solo iman con un punto consecuente en su mitad.

Si la espiral se mueve con relación a ese sistema, se comprende según lo dicho anteriormente, que la espiral será recorrida por una corriente positiva durante el primer cuarto del movimiento entre A i M, por una corriente negativa en el segundo cuarto, de $\mathrm{M}$ a B, todavía por una corriente negativa en el tercer cuarto, de B' a M', i en fin, por una corriente positiva durante el último cuarto, de M' a A'. En los puntos neutros la corriente cambia de sentido.

Estos hechos esperimentales que vamos a considerar aun bajo una nueva faz, son la clave de la máquina de Gramme.

Supongamos que tenemos un anillo de hierro dulce (Figura 2) $n n$, colocado de tal manera entre las ramas de un iman vertical en forma de herradura A M B, que su diámetro horizontal coincida con la línea A B, suponiendo imaginariamente unidos los polos del iman. La influencia de esos polos determina en cada uno de los semi-anillos $b n a$, b' n' a', una imantación por influencia; de donde resulta, frente al polo A, la producción de un doble polo boreal $b b^{\prime}$, frente al polo B, la producción de un doble polo austral $a^{\prime}$ $a$, en fin, en $n$ i $n$ ' se tienden dos rejiones neutras.

Supongamos también que, estando fijo el anillo, se haya enrollado en torno de uno de sus puntos una pequeña espiral s compuesta de un hilo metálico cubierto de seda, i que esta espiral pueda resbalar sobre el anillo según el sentido indicado por la flecha, de manera que tome sucesivamente las posiciones $n, b b^{\prime}, n^{\prime}, a a^{\prime}$, $n$, etc.; supongamos por último, que las estremidades del hilo estén reunidas por un circuito conductor que comprenda un galvanómetro. Si a la espiral se la cambia de lugar de una manera sucesiva, procediendo por ejemplo, por pequeños cambios correspondientes cada uno a un arco de 10 grados, la esperiencia demuestra que se produce una série de corrientes inducidas, cuyo sentido es constante durante la semi-revolucion $n b b^{\prime} n^{\prime}$ que se efectúa 
hácia la derecha de la vertical que pasa por la línea neutra. Durante la semi-revolucion n' a' a n que efectúa a la izquierda, las corrientes tienen también un sentido constante, pero inverso del primero.

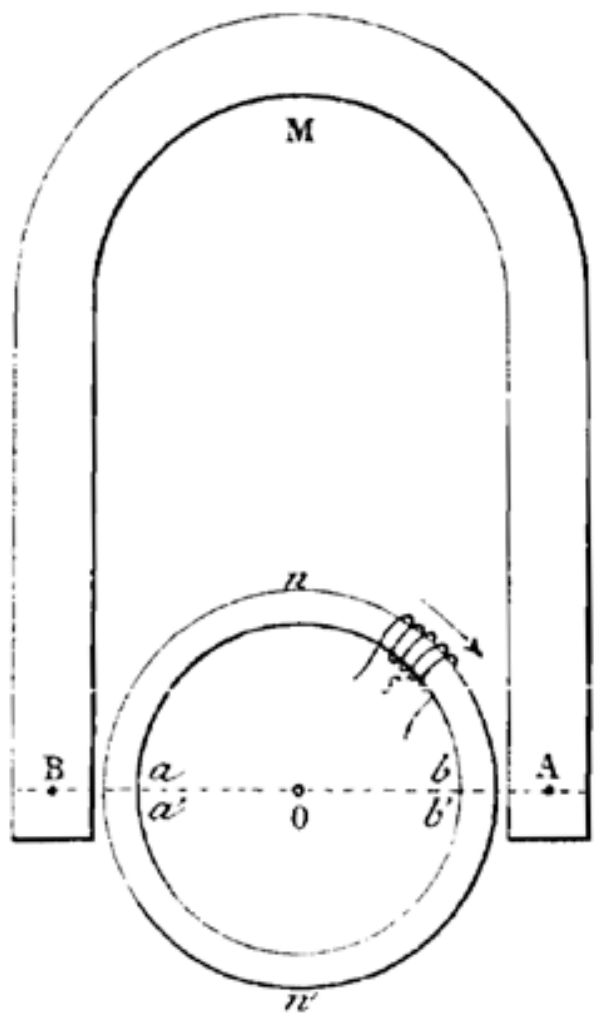

Figura 2

Para darse cuenta de lo que pasa en esta série de fenómenos, basta recordar el esperimento anterior i fijarse en la distribucion del magnetismo en el iman, notando que con respecto a esa distribucion las corrientes en el fierro dulce deben considerarse como circulando en un mismo entido en la porcion $a n b$ i en sentido contrario en la porcion $a^{\prime}$ n' b'. Es sabido, que según la lei de Lenz siempre que se hace cambiar de posicion un circuito cerrado en la cercania de una corriente o de un iman, se desarrolla en ese circuito una corriente de sentido contrario a la que hubiera podido producir ese mismo cambio de lugar del iman. Esta lei conduce a considerar el movimiento de la espiral $s$ como desarrollando en el hilo, durante el cuarto de revolucion $n b$ que la acerca hacia $b$, una corriente del mismo sentido que las corrientes particulares de la porcion del anillo $n b$; durante el cuarto de revolucion b' n' que la aleja de b', una corriente de sentido contrario al de las corrientes particulares de la porcion de anillo b' n'; es decir, en el mismo sentido que las precedentes. Las mismas consideraciones muestran que el sentido de las corrientes de la espiral se invierte durante el movimiento n' a' a n. Tampoco cambiarian 
los fenómenos si fijando la espiral al anillo, se imprime a éste un movimiento de rotación en torno de un eje $\mathrm{O}$ perpendicular a su plano i que pase por su centro; en ese caso los polos dobles $b b^{\prime}$ i $a$ a' ocuparán siempre una posicion fija en el espacio, teniendo la espiral $s$ que ocupar todas las posiciones posibles con relación a esos dos puntos. Tal es el movimiento adoptado en la máquina de Gramme.

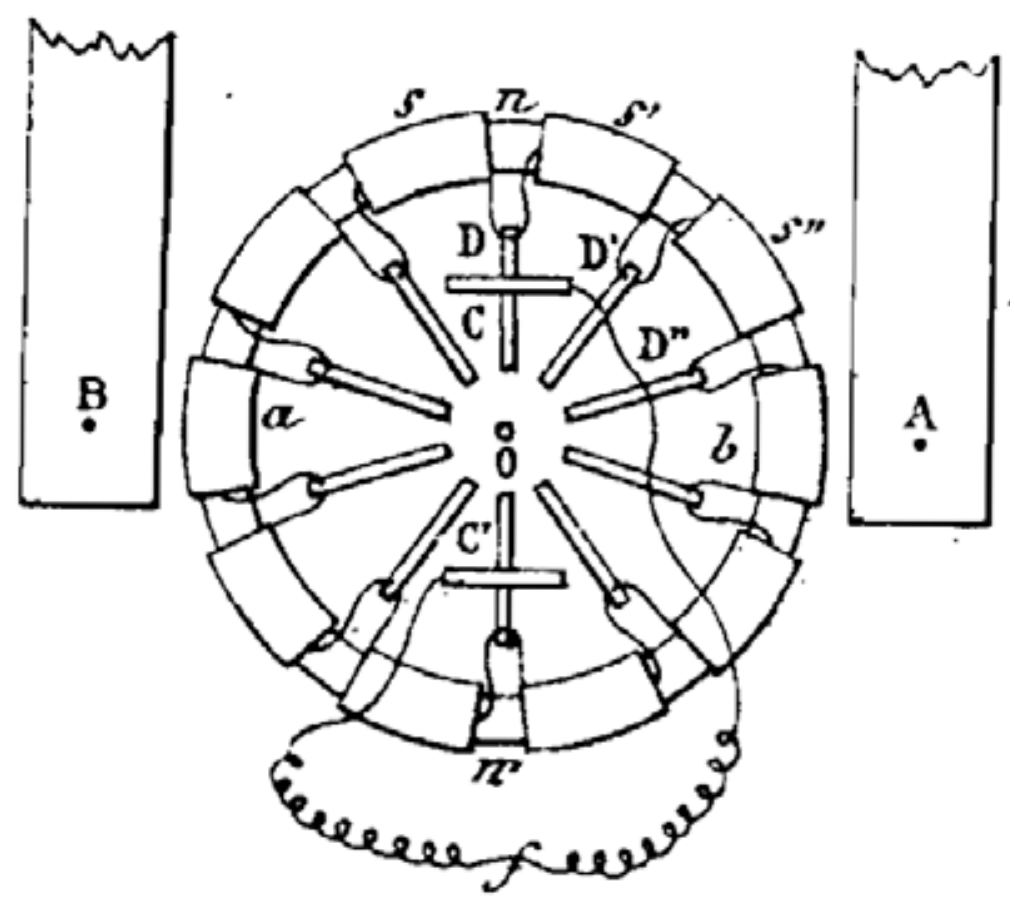

Figura 3

Así, fíjense en el anillo nó una sola espiral, como se vé en la Figura 2, sino una série de espirales (Figura 3) i suéldense a las piezas de cobre D, D', D", etc. las estremidades, iniciales de las espirales s, s', s", etc. estando además sujeto el sistema de piezas de cobre al anillo, de manera que sea arrastrado por él en su movimiento jiratorio alrededor del eje O. Dispóngase, por último, en una posicion fija i en la vertical que pasa por el punto $\mathrm{O}$, dos láminas metálicas $\mathrm{C}, \mathrm{C}^{\prime}$ de manera que durante el movimiento de rotación se encuentren siempre respectivamente en contacto con las dos piezas radiales de cobre, correspondientes en posicion a la línea neutra $n$ n'. Se vé claramente que estando reunidas las dos láminas $\mathrm{C}$ i C', por un conductor $f$, en cada período de la rotación, los dos sistemas de espirales situados, el uno a la derecha i el otro a la izquierda de $n n^{\prime}$, podrán ser asimilados a dos sistemas de elementos de baterías voltáicas asociados en série; las dos séries teniendo, una i otra sus polos positivos en una de las láminas C, i sus polos negativos en la otra lámina C'. 


\section{MÁQUINA DE GRAMME EMPLEADA EN LOS LABORATORIOS}

La Figura 4 nos muestra la disposición jeneral que se da a la máquina de Gramme con imanes, aunque representa un modelo de mui pequeñas dimensiones.

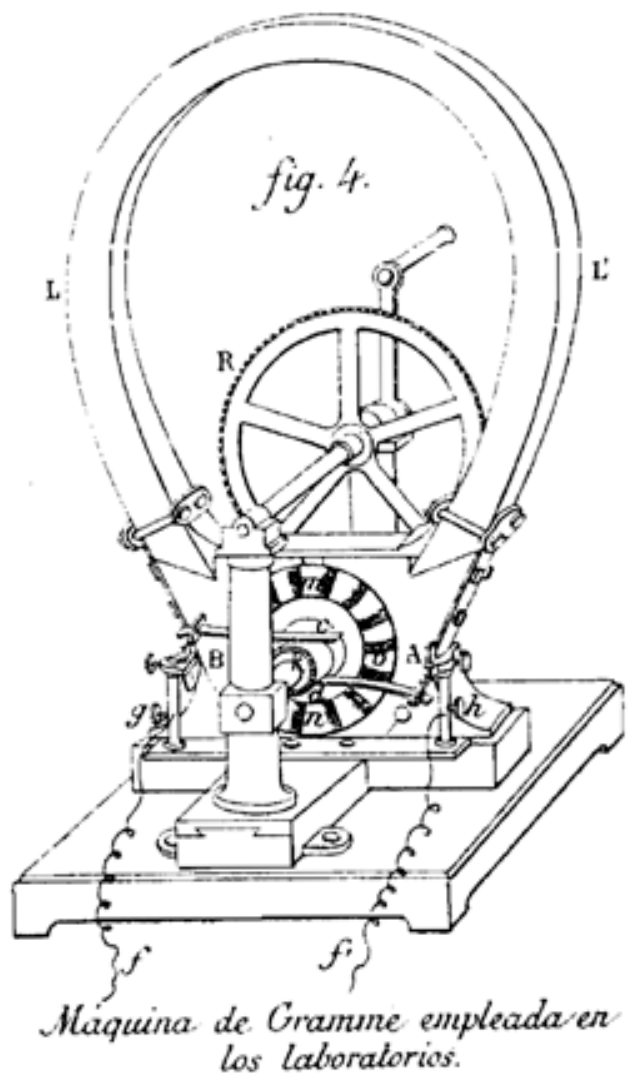

Figura 4

El iman L L' es un iman Jamin, cuyas armaduras A i B constituyen los polos entre los cuales jira el anillo $m b n$. Las tintas alternadas de claro i oscuro representan en el dibujo las espirales sucesivas aplicadas en el anillo de fierro dulce, anillo que está formado de un haz de alambres de hierro soldados. Las piezas radiales de cobre a las cuales están soldadas las estremidades de los hilos de las espirales se prolongan hácia adelante del anillo, formando un cilindro $k$ de diámetro menor; están aisladas por cintas de seda $\mathrm{u}$ otra materia aisladora. Sobre el cilindro $k$ apoyan, en las dos estremidades de un diámetro perpendicular a la línea de los polos A B, dos láminas $c d$, o mas bien dos escobillas de hilos metálicos sujetas en las columnas fijas $g, h$, $a$ las que se unen los conductores $f$ if', que permiten dar paso a la corriente desarrollada en la máquina, a un aparato cualquiera. 
Como los hilos metálicos que forman las escobillas $c$ i $d$ son bastante flexibles, tocan simultáneamente varias de las piezas de cobre cercanas, dando por resultado que la corriente nunca se interrumpa; i además así se suprime la resistencia de las espirales vecinas a la línea neutra, evitándose de esta manera la disminución de intensidad en la corriente total; puesto que las corrientes desarrolladas léjos de los polos son siempre mui débiles.

Se imprime el movimiento al anillo por medio de una manivela i de una rueda dentada R que engrana con un piñon fijo al anillo, obteniéndose así con facilidad una velocidad que alcanza a cientos de vueltas por minuto.

Con este aparato se puede poner incandescente un hilo metálico de algunos centímetros de lonjitud, i realizar la mayor parte de los esperimentos que exijen el empelo de 8 a 10 elementos de Bunsen.

\section{MÁQUINA DE GRAMME SIN IMANES I CARÁCTER ESPECIAL DE LAS QUE SE EMPLEAN EN EL ALUMBRADO}

En la industria se las construye con electro-imanes a los que se puede dar una enerjía mucho mayor que la de los imanes. Debe advertirse que no es necesario emplear, para hacer que se desarrolle i conserve el magnetismo en el electro-iman inductor, un manantial de electricidad por separado. Basta introducir permanentemente el hilo del electro-iman en el circuito formado por los conductores que debe recorrer la corriente inducida. Puesta en movimiento la máquina, adquiere casi instantáneamente una enerjía que crece con la velocidad de rotación.

De lo anterior se deduce que el electro-iman inductor debe poseer ántes que empiece el movimiento, una débil imantación debida ya a la acción del magnetismo terrestre, ya al magnetismo remanente; pero que basta para desarrollar en el momento de la rotación una corriente inducida que desarrolla a su vez en el electro-iman una imantación cada vez mayor, hasta que la máquina adquiere su réjimen normal.

La Figura 5 es el tipo de las máquinas que generalmente se emplean para la producción de la luz eléctrica. Cuando se las destina a la galvanoplástica el hilo de las espirales es mas corto i de mayor diámetro.

Como se vé, la máquina tiene dos electro-imanes inductores, el uno A B, a la izquierda, el otro A' B' a la derecha. Los polos del mismo nombre A i A', corresponden a una misma armadura de hierro dulce, haciendo de esta armadura un polo austral único; así mismo los polos B i B', aplicados en B constituyen de la misma manera un polo boreal.

Con el objeto de introducir los electro-imanes en el circuito recorrido por la corriente inducida, se fija en la pieza de cobre $m$ uno de los hilos que sirven para formar el circuito; esta misma pieza de cobre, aislada de las armaduras alfa $i$ beta recibe el hilo $g$ que recorre sucesivamente las bobinas A', B', B, A, i termina en el montaje de la escobilla que cierra definitivamente el circuito.

La máquina recibe jeneralmente su movimiento de un motor de vapor, cuyo árbol o volante lleva una correa sin fin que pasa por el tambor P. 


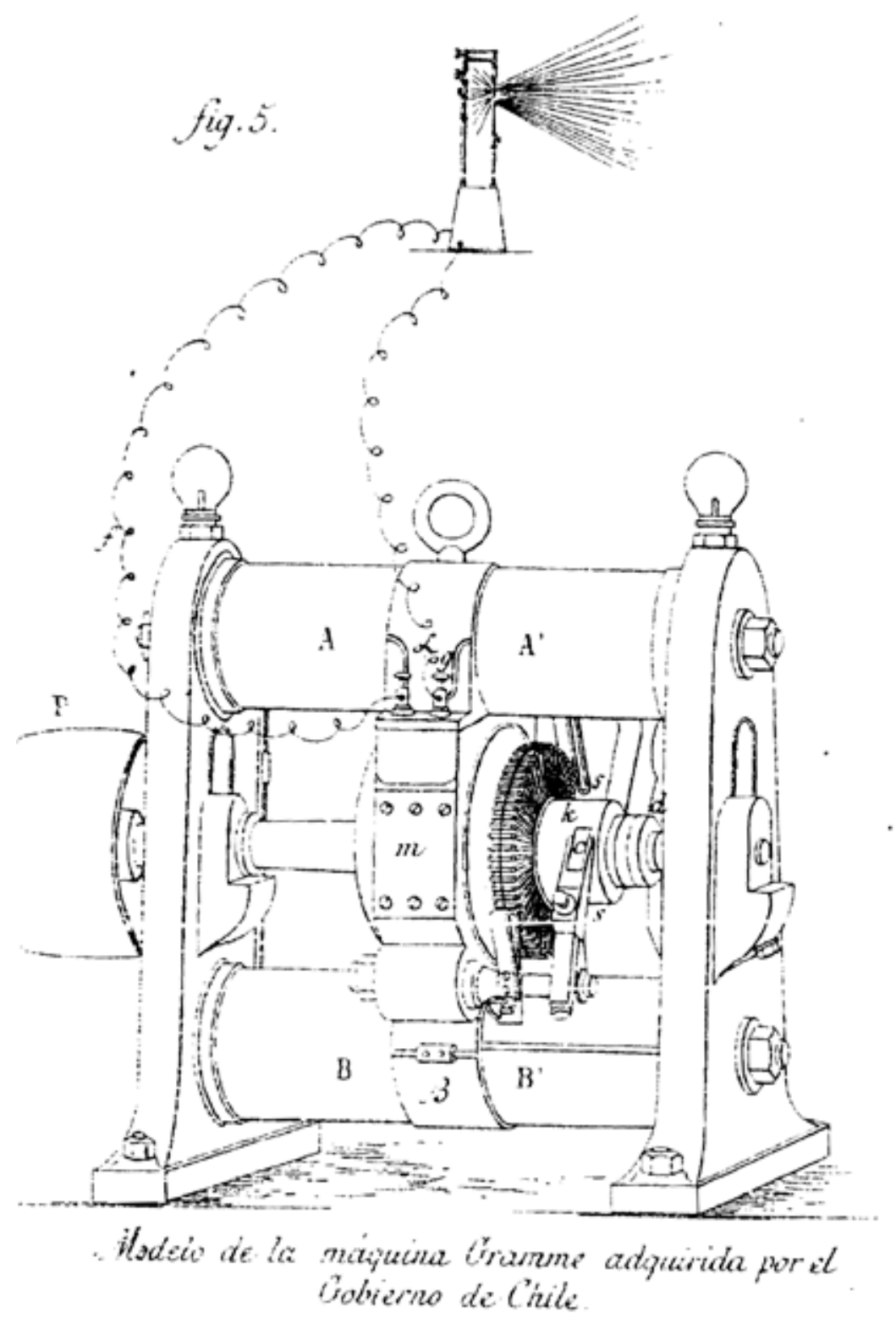

Figura 5 
Tambien se emplean otros tipos o disposiciones en las máquinas de Gramme, sin que por esto cambie absolutamente el principio teórico de ellas. Las hai verticales con las bobinas i los electro-imanes dispuestos de una manera diferente; las hai constituyendo la parte anterior de un motor de vapor horizontal i recibiendo el movimiento de éste por medio de una biela; en fin, a veces la máquina Gramme forma parte de una verdadera locomóvil, sistema Brotherhood, disposición que como su nombre lo indica, se presta a un cómodo trasporte.

En cuanto al poder, las mas empleadas en el alumbrado eléctrico son las que producen una luz que equivale a 100 quemadores de Carcel ${ }^{10}$ pero se construyen máquinas que equivalen a 1,000, 2,000 i aun 10,000 quemadores de Carcel. Esto naturalmente depende del empleo a que se las destina.

\section{TRANSFORMACION DE LA ELECTRICIDAD EN TRABAJO}

Ya tenemos dicho que la máquina de Gramme, como todas las demás máquinas magneto-eléctricas, tienen por objeto principal transformar la fuerza mecánica en electricidad; pero las de Gramme pueden también transformar la electricidad en fuerza motriz i hacer en ese caso el papel de máquinas electro-magnéticas. El hecho es, consignando únicamente el fenómeno, que basta poner un manantial eléctrico cualquiera en comunicación con las escobillas metálicas de la máquina de Gramme, para que el anillo central se ponga inmediatamente en movimiento.

Bastando mui poca fuerza motriz para equilibrar un gran número de elementos voltáicos, resulta recíprocamente que serán necesarios muchos de esos elementos para obtener poco trabajo mecánico. Por esto es que siempre se ha tenido mal resultado cuando se ha querido obtener fuerza motriz por medio de la electricidad.

Pero de lo espuesto se desprende que se podría mui bien, valiéndose de máquinas de Gramme, trasportar fuerzas motrices a gran distancia.

Se han hecho esperimentos en Paris con una máquina magneto-eléctrica, puesta en movimiento por un motor de vapor que tenía que desarrollar una fuerza de 75 quilográmetros para ponerla en movimiento; la electricidad producida era enviada a una segunda máquina que produjo 39 quilográmetros, medidos con el freno de Prony, es decir, un poco mas de la mitad de la fuerza primitiva. Como la electricidad pasaba por dos máquinas, o, lo que es lo mismo, como había una doble transformación del trabajo en electricidad i de la electricidad en trabajo, cada máquina producía un efecto útil superior a un 70 por ciento.

Sin embargo, estas cuestiones vienen a constituir una nueva rama de aplicaciones, i aun no han sido bien estudiadas para que se las pueda considerar como absolutamente aplicables bajo un punto de vista económico. No obstante hai en ellas un nuevo horizonte que se prepara i que puede dar lugar al desarrollo de muchas industrias.

10. El quemador Carcel es el tipo de comparacion para las medidas fotométricas; consume 42 gramos de aceite puro de Colza por hora. 


\section{ARCO VOLTAICO}

Acercando uno a otro los dos conductores de un manantial de electricidad suficientemente intenso hasta que se toquen, i alejándolos en seguida gradualmente, se vé aparecer un arco luminoso, mui brillante, que persiste mientras la distancia entre los dos conductores no es mui grande. Este arco ha recibido el nombre de arco voltáico, en recuerdo de la pila con la cual se obtuvo por vez primera.

Este es hoy casi el único método que se emplea para tener luz eléctrica. La brillantez del arco voltáico depende de la intensidad de la corriente, de la naturaleza de los electrodos i del medio en el cual se produce. Con el potassium o el sodium por ejemplo, la luz es mas brillante que con el platino o el oro; en el aire se tiene mas luz que en una atmósfera de vapores mercuriales.

El color del arco varía con la naturaleza de los electrodos: es amarillo con el sodium, blanco con el zinc, verde con la plata.

El aspecto del foco depende de la forma de los electrodos: entre dos puntas de carbón la forma es ovoide, i en realidad el arco voltáico no es sino una porcion del circuito eléctrico con todas las propiedades de las otras partes del mismo circuito. Las moléculas de carbono arrastradas por la corriente constituyen entre las dos puntas una cadena móvil mas o ménos conductora i mas o ménos caliente, según la intensidad de la corriente por una parte, i la naturaleza i distancia de los electrodos por otra. Puede decirse que la luz producida por el arco voltáico i la que se obtiene por incandescencia provienen de la misma causa, cual es el calentamiento de un cuerpo resistente intercalado en el circuito; i que el foco voltáico está formado de verdadero vapor de carbono.

En efecto, la luz eléctrica no debe sus propiedades especiales sino a la condensación de una gran cantidad de calor en un espacio mui pequeño. Este calor proviene de la combustión del zinc cuando se emplea la pila, o del hogar de la máquina de vapor que pone en movimiento el aparto magneto-eléctrico. Condensar el calor en un pequeño espacio de manera que se eleve mucho la temperatura de los cuerpos, tal es el problema relativo a la producción de la luz. La electricidad es el mejor medio que pueda emplearse para llegar a ese resultado.

La luz eléctrica que obtiene entre dos puntas de carbón, tiene una gran analojía, en cuanto a los efectos que produce, con la luz del sol, i en cuanto a intensidad, la luz del arco voltáico llega a la mitad de la que nos envia ese astro en tiempo despejado; comparándola fotométricamente, es decir, considerando el poder emisivo por metro cuadrado del cuerpo luminoso i no del total de la luz desarrollada.

Sin embargo de lo espuesto, la luz eléctrica no ha venido a tener aplicaciones industriales sino desde el momento en que se la ha podido producir con facilidad i a poco costo relativamente. Este momento parece que ha llegado hoi con la máquina Gramme, que con tanta ventaja reemplaza el engorroso empleo de las baterías voltáicas, cuyos defectos todo el mundo conoce, i con la invención de los múltiples e injeniosos reguladores o lámparas que llevan los electrodos. Entre éstos, solo nos consagraremos a describir uno de los mas cómodos, sencillos i que con preferencia se emplean siempre que el manantial de electricidad es la máquina Gramme; nos referimos al de M. Serrin. 


\section{REGULADOR SERRIN}

Para obtener la luz eléctrica entre los dos carbones de la lámpara o regulador, es necesario ante todo que las puntas estén en contacto, para que se establezca la corriente eléctrica; es necesario colocarlas en seguida a una pequeña distancia una de otra, para que el arco eléctrico pueda desarrollarse; en fin, es necesario que constantemente se acerquen a medida que se consuman por la combustión o el trasporte eléctrico, de suerte que el foto de luz ocupe siempre una posicion invariable.

El regulador de M. Serrin satisface plenamente esas tres condiciones. Deja los carbonos en contacto cuando la corriente no circula; los separa a la distancia requerida cuando se establece la corriente; los acera en seguida constantemente sin que halla contacto. Si por una causa accidental se quiebran los carbones, o se separan demasiado, vuelven automáticamente, después de un instante de contacto a la distancia que debe separarlos para que el arco se desarrolle con toda brillantez.

La Figura 6 representa el aparato. Se compone de un electro iman A, de una varilla $B$ que sirve de motor, de una varilla $C$ que lleva el carbón negativo, de una armadura $\mathrm{D}$, de un tope $\mathrm{E}$ de una atadura $F$, de un tornillo excéntrico $G$, de un soporte $\mathrm{H}$ para el carbón positivo, de un atravesaño fijo I, de uno que se puede alargar J, de una palanca de tensión KL, de un doble paralelogramo MNPQ, de un aparato de relojería $\mathrm{O}$, de un tornillo $\mathrm{R}$, de un tornillo de corrección $\mathrm{S}$, de un tornillo de unión $\mathrm{T}$, de un tope de marfil $\mathrm{V}$, que

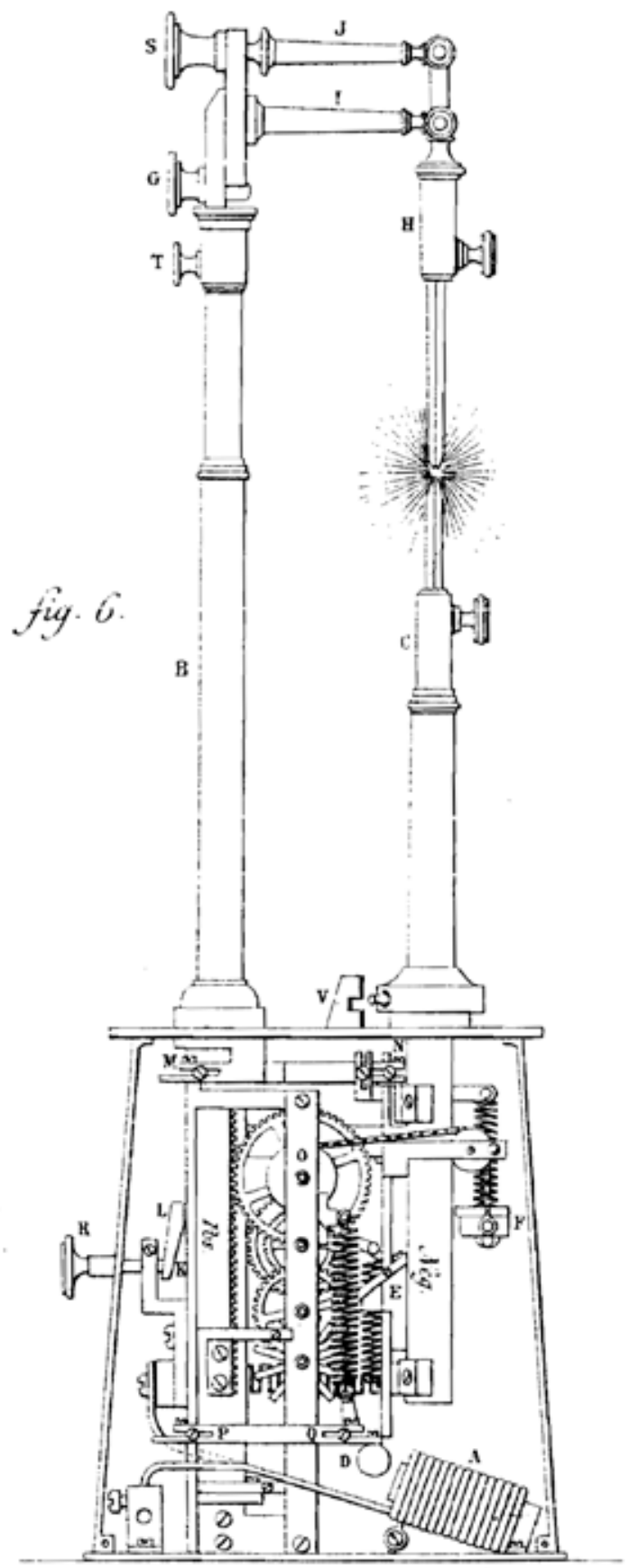

Requlador Serrin

Figura 6 
sirve para detener el movimiento en la lámpara, de una cubierta de bronce, i de una serie de detalles accesorios.

Los carbones se fijan por medio de tornillos de presión en dos pinzas. El carbón positivo se mantiene sobre el carbón negativo sostenido por una varilla cilíndrica maciza, provista en la parte superior de dos atravesaños horizontales que están unidos al portacarbon. El atravesaño superior permite, valiéndose de un tornillo especial, imprimir al porta-carbon un movimiento en un plano paralelo al dibujo. El atravesaño inferior, por medio de un excéntrico que depende del botón $G$, mueve el carbón en un plano vertical perpendicular al plano de la figura. La combinación de esos dos movimientos rectangulares entre sí, permite colocar rigurosamente en presencia uno de otro las dos puntas de carbón. Entre ellos se produce el arco voltáico que se mantiene constantemente a la altura de una gargantita circular tallada en la varilla maciza del porta-carbon positiva.

El porta-carbón negativo vá introducido en un tubo que lleva un tornillo de presión para sujetar el carbón.

El acercamiento de las puntas de los carbones i su mantenimiento a una distancia conveniente se obtienen sin dificultad.

La varilla maciza del porta-carbón positivo tiende a descender verticalmente bajo la acción de la pesantes. Su parte inferior está tallada como cremallera, i mientras desciende engrana con una rueda dentada $\mathrm{O}$ que comunica el movimiento al sistema de engranajes figurado en el dibujo. El árbol $O$ de la primera rueda lleva una polea de un diámetro que es la mitad del de la rueda. Esta polea sigue el movimiento i lo transmite por medio de una cadenilla sistema Vaucason, a otra poleita de transmisión; la cadena está fija a una pieza F, unida al tubo del porta-carbon negativo. A causa de las dimensiones i de la disposición de la primera polea, el porta-carbon positivo se mueve de abajo a arriba una cantidad que es casi la mitad de lo que desciende el porta carbón positivo. Así se compensan las diferencias en el uso de los carbones, que, como se sabe, el del negativo es la mitad del positivo.

El movimiento del carbón positivo se regulariza por medio de un sistema de engranajes que termina en un piñon del cual dependen a la vez, un regulador con aletas i un volante estrellado cuyo rol importante vamos a ver.

Cuando se quiera renovar los carbones, se levanta la varilla maciza del carbón positivo: al mismo tiempo bajará el tubo del carbón negativo por la acción de su propio peso, i el sistema está arreglado de tal manera que los engranajes permanecen en reposo.

Para obtener el mantenimiento de la distancia conveniente entre las puntas, sirven el doble paralelogramo articulado MNPQ, la armadura de hierro dulce D i el electro-iman A.

En el paralelogramo, el lado vertical MQ cercano del porta-carbon positivo, está fijo; los lados, MN, PQ, pueden separarse de la dirección horizontal; el tercer lado N P es vertical i las estremidades inferiores de esos lados verticales móviles, están unidos por una armadura de hierro dulce $\mathrm{D}$.

La influencia de la pesantes sobre el paralelogramo articulado es contrabalanceada por dos resortes en espiral, encontrándose uno de ellos, como se vé en la figura, unido a la estremidad de una palanca acodada LK, que un tornillo esterior R permite levantar a voluntad. 
La armadura de hierro dulce D, colocada frente al electro-iman A, será atraída por este último al cerrarse el circuito, i la intensidad de esta atracción variará con la enerjia de la corriente.

El hilo positivo de la máquina, sujeto a un tornillo, queda en comunicación con la masa del aparato, i la corriente pasando del carbón superior positivo al carbón inferior negativo, por el arco voltáico vá del porta-carbon inferior, atravesando el conductor aislado S, al electro-iman, i sale del aparato por un tornillo aislado, al cual está unido el hilo negativo.

El tubo del porta-carbon negativo está unido al lado vertical móvil del paralelogramo. Este queda sometido a dos esfuerzos que se contrabalancean: su peso que tiende a hacerlo oscilar en torno de la arista fija, i los resortes que tienden a levantarlo. La acción del electro-iman consiste en triunfar en un momento dado de la potencia de los resortes i atrayendo la armadura de hierro dulce hacer descender el paralelogramo. Cuando la corriente del electro-iman se debilita, los resortes vencen a su vez i levantan el paralelogramo.

En el primer caso que hemos considerado el carbón negativo desciende i en el segundo se levanta. En efecto, el lado vertical del paralelogramo lleva una escuadra E, cuya estremidad puede, descendiendo, penetrar entre los brazos del molinete, enrayar el movimiento de los engranajes i por consiguiente de la cremallera. Levantándose el paralelogramo deja libre la escuadra i de aquí los dos resultados diferentes.

El botón R obra por medio de la palanca L K sobre un resorte que sirve para regular el aparato. Cuando la luz aparece entre las dos puntas de carbón, se separan i a esta posicion corresponde una posicion del paralelogramo unida a las acciones de los resortes i electro-iman. Haciendo variar por medio de la palanca la tensión del resorte i la distancia de la armadura del electro-iman, se fija con facilidad la conveniente posicion del paralelogramo i las distancias de las puntas en las condiciones más favorables.

Para comprender bien la manera de funcionar del aparato, supondremos que los carbones hayan sido colocados sin que la corriente pase por el aparato. El movimiento de descenso de la varilla maciza determina el movimiento ascensional del carbón negativo hasta el contacto. Desde ese momento descienden al mismo tiempo, pero como la varilla del carbón negativo está unida al lado vertical del paralelógramo, lo hace descender, la escuadra enraya al molinete i el mecanismo se inmoviliza.

Cuando la corriente pasa por el aparato, la armadura será atraída por el electroiman, arrastrará al paralelógramo i al carbón inferior, cuya punta se separará del superior: entonces aparecerá el arco voltáico uniendo las dos puntas. A medida que la corriente se debilita por el uso i separación de los carbones, el electro-iman se debilita también, vencen los resortes, la armadura se aleja i el paralelógramo se levanta. A causa de este incesante movimiento del paralelógramo que ya desciende, ya sube, el molinete alternativamente es arrastrado o queda libre; la cremallera por consiguiente, pasa por alternativas de descenso e inmovilidad, i el mecanismo que tiende a unir los carbones funciona manteniendo constantemente a éstos en los límites requeridos.

Con carbones químicamente puros i una fuente de electricidad constante, se puede obtener una luz tan fija como la de una lámpara de aceite o la de un buen quemador de gas. 


\section{LÁMPARA DE MANO}

No hemos descrito otros reguladores que satisfacen plenamente las mismas condiciones que el de M. Serrin, como los de Foucault, de Gaiffe, etc., porque esos instrumentos no reúnen las condiciones de solidez i simplicidad que requieren los aparatos industriales.

No obstante, hai ocasiones en las cuales el uso de un regulador, por bueno que sea, es engorroso por el peso i condiciones de relativa estabilidad en que debe ser mantenido. Ademas, muchas veces solo se requiere tener una luz de poca intensidad, pero de fácil movilidad i que sea posible dirijir con prontitud a un punto dado.

Con este objeto emplean en las marinas de guerra francesa e inglesa, lámparas de mano en las cuales uno de los carbones permanece fijo, el negativo o inferior, i el otro es movible a la mano, de manera que a medida que se consumen los carbones se van acercando para que persista la luz. Estas lámparas llevan lentes destinados a reunir los rayos luminosos en un haz paralelo, i a veces un prisma de refleccion total que impide toda pérdida de luz.

La sencillez de esos aparatos nos dispensa el entrar en mas detalles acerca de su construcción. Tambien omitimos describir muchos otros aparatos de gran interés empleado en el alumbrado eléctrico, como las bujías de M. Jablochkoff por ejemplo, porque esa descripción nos sacaría de los límites que nos hemos impuesto.

\section{REFLECTORES Y PROYECTORES}

Empléanse diversos sistemas para esparcir o proyectar la luz de un regulador o lámpara de mano en un recinto o lugar dado. Guiándonos el deseo de que la luz eléctrica se emplee en nuestra marina de guerra, solo describiremos el proyector lentienlar de Sautter i Lemonier, que es el aparato de mejores condiciones, tratándose del alumbrado marino.

Este proyectos que representamos en la (Figura 7), reconcentra los rayos luminosos que emanan de la lámpara en un haz cilíndrico, i permite al operador dirijir la luz a un punto cualquiera del espacio.

El arco voltáico del regulador Serrin está colocado en el foco de una lente de Fresnel de 0m,60 de diámetro, compuesta de tres elementos dióptricos i de seis elementos catadióptricos. La lámpara i lente están colocadas en un tambor de hierro fundido movible en torno de su eje vertical, i pudiendo oscilar en torno del horizontal, sin que cambien las posiciones relativas de la lámpara i lente; de lo cual resulta que, tanto en reposo como en movimiento, el punto luminoso permanece en el foco óptico, i sus rayos continúan siendo arrojados en el espacio, según un haz en la dirección del eje óptico de la lente.

Los diversos movimientos pueden ser sucesivos o simultáneos; tienen por objeto dirijir el eje óptico, i por consiguiente el haz luminoso en todas las direcciones i según todas las inclinaciones.

El operador efectúa estas maniobras valiéndose de dos manillas cómodamente dispuestas. 


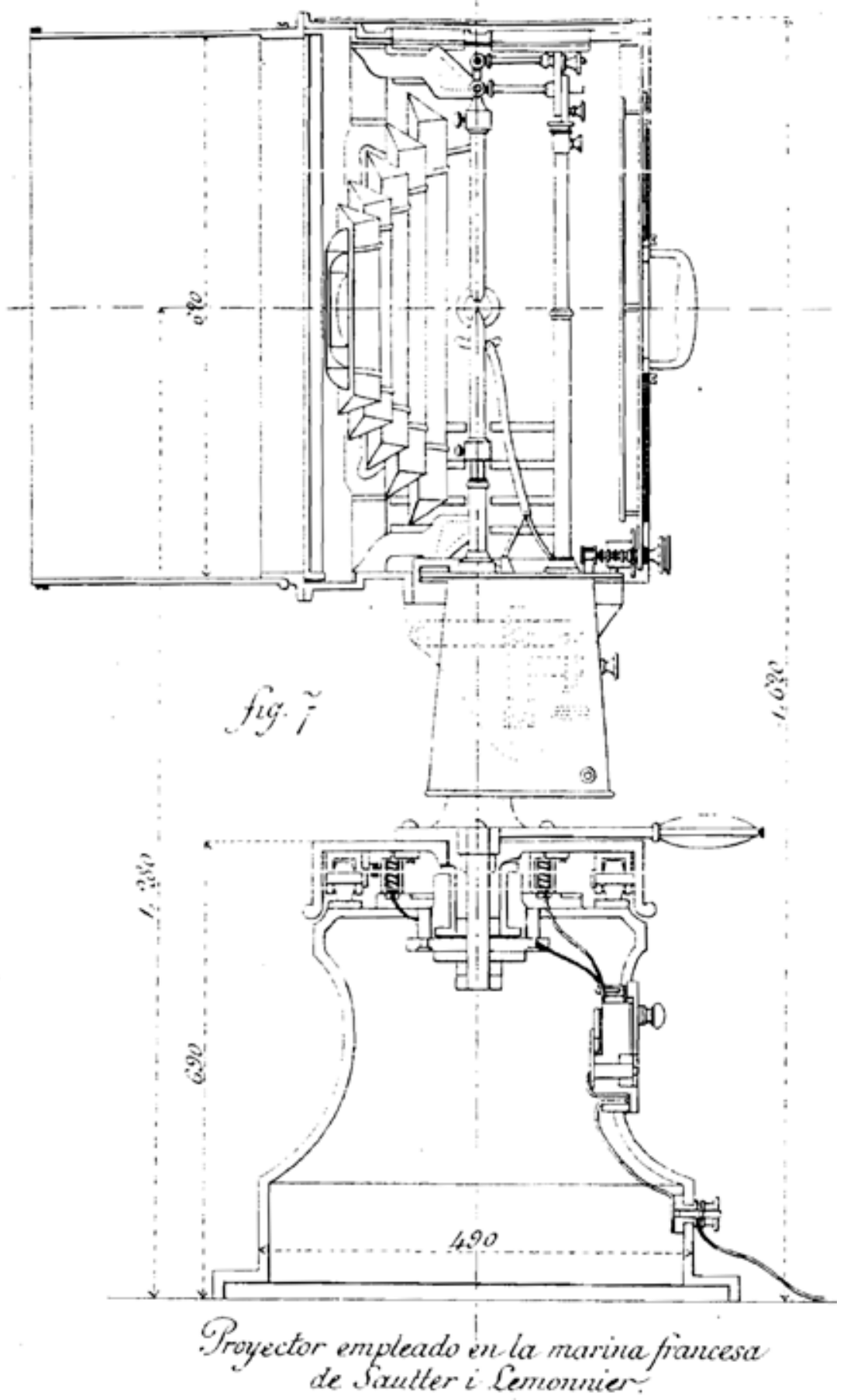

Figura 7 
Por el solo hecho de su instroduccion en el aparato, la lámpara queda en el circuito eléctrico i no cesa de encontrarse, sean cuales fueron los movimientos impresos al cilindro móvil.

Un pequeño anteojo colocado en uno de los lados del aparato, proyecta sobre una pantalla de vidrio opaco la imájen de los carbones, i permite seguir la marcha de la lámpara sin necesidad de abrir el cilindro. Un tornillo permite variar la posicion de la lámpara cuando se trata de colocar el foco el punto luminoso o quitarlo para producir una diverjencia mas o ménos grande en el haz. Un segundo tornillo i una manilla sirven para mantener el haz en una dirección determinada.

Cuando se le emplea en la artillería, una disposicion especial permite cambiar lentamente, por medio de tornillos de tanjencia, el haz luminoso i llevarlo exactamente segun una direccion determinada de antemano.

El aparato se coloca sobre un zócalo de hierro fundido que se fija en el puente del buque, nó en las cofas como vulgarmente se cree; en el interior de una casa-mata en un fuerte, o sobre un carro móvil. Por medio de un interruptor se suprime cuando se quiere la corriente, sin que haya necesidad de detener el movimiento de la máquina.

\section{CARBONES ELÉCTRICOS}

Davy se servia para obtener la luz eléctrica, de lápices de carbon de madera que producían un hermoso arco voltáico, pero que se consumían con gran rapidez. Foucault, reemplazando el carbon de madera con los depósitos recojidos en las retortas del gas alumbrado, abrió realmente al arco voltáico la era de las aplicaciones útiles. El carbon de retorta, como mas denso, resiste mucho mas tiempo la acción destructora del foco eléctrico. Tiene sin embargo, sérios inconvenientes, porque su composicion no es homojénea; por eso decrepita a veces i se gasta desigualmente, pero en la mayor parte de los casos el carbon de las retortas dá excelentes resultados.

Se ha tratado de reemplazarlos por aglomerados análogos pero mas puros, o bien se ha procurado purificarlos. El único inconveniente de estos productos, superiores al carbon que directamente se estrae de las retortas, es su precio elevado.

Un dato que no carece de interés relativo a los carbones, es el siguiente: una máquina magneto-eléctrica que alimente un solo regulador i que absorba dos i medio caballos de fuerza motriz, consume en Francia fr. 0,25 de lápices de carbon por hora.

\section{CONDUCTORES}

Deben ser de cobre por la buena conductibilidad de este metal para la electricidad, i si es posible cubiertos de gutta-percha i algodón alquitranado. El diámetro que deben tener para disminuir la resistencia al pasaje de la corriente, dependerá de la distancia a que se encuentren las lámparas de la máquina magneto-eléctrica.

La fórmula jeneral que indica el valor de la intensidad de una corriente, i que en breve discutiremos, nos dará una idea acerca del diámetro que debe darse a los conductores. 


\section{INSTALACION JENERAL; COSTO DEL ALUMBRADO ELÉCTRICO I REGLAS RELATIVAS AL MANEJO DE LOS APARATOS}

Ya hemos visto que para hacer funcionar las máquinas magneto-eléctricas, basta ponerlas en movimiento por medio de un motor que en la jeneralidad de los casos será de vapor; i para obtener la luz, reunir los dos electrodos del aparato, por medio de conductores, con los respectivos polos de la lámpara o regulador. La Figura 8 muestra la disposicion que debe darse a los diversos aparatos.

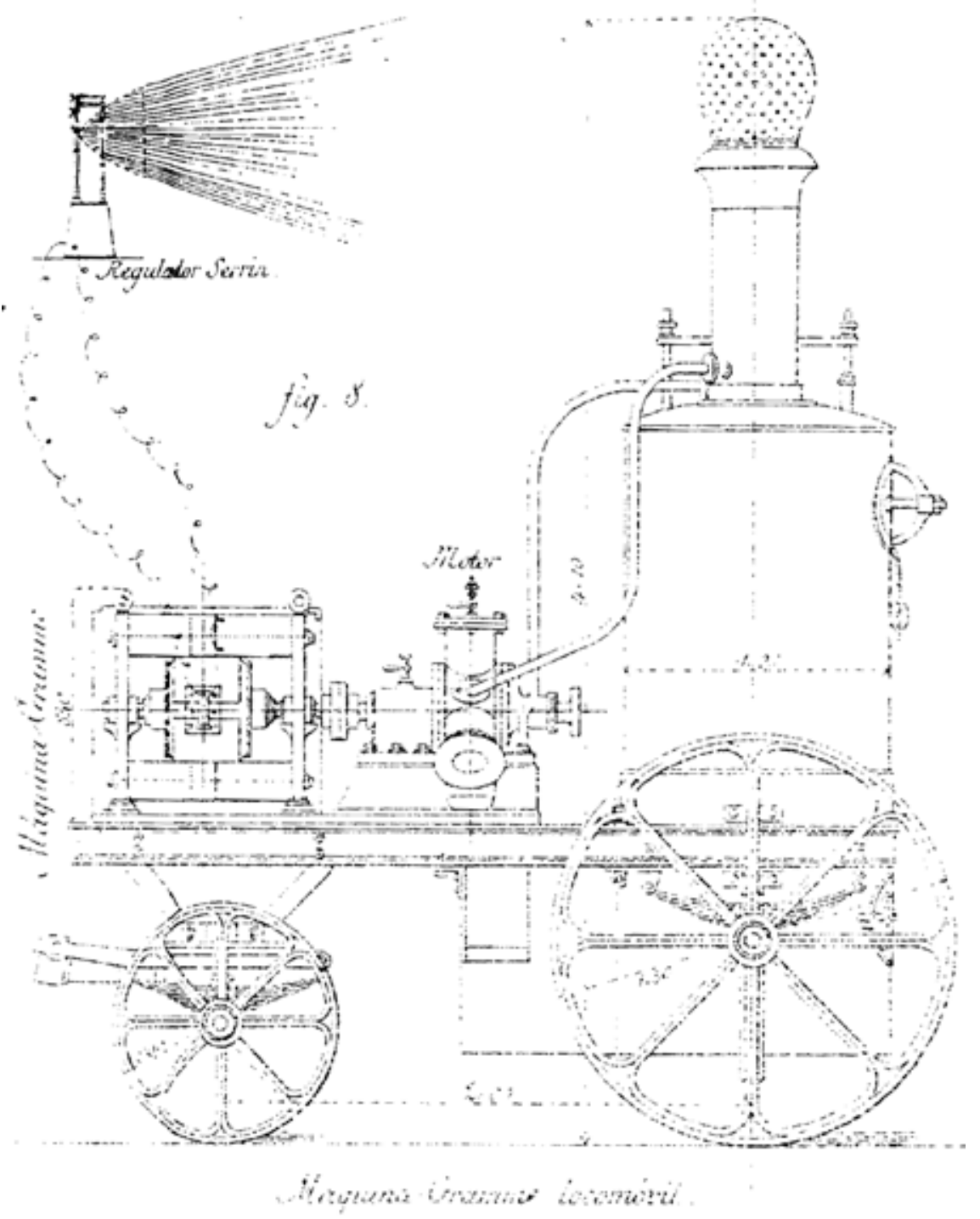

Figura 8 
Se han hecho gran número de esperimentos con el objeto de determinar la cantidad de trabajo absorbido por las máquinas de Gramme; pero en ninguno de ellos se ha obtenido resultados precisos i concordantes a causa de las dificultades que ofrece el medir rigurosamente la cantidad de luz emitida por un foco cualquiera, i la no menor de calcular el trabajo motor en el momento mismo del esperimento fotométrico.

A pesar de estas dificultades, se ha podido comprobar que con una fuerza de tres caballos de vapor, se pueden obtener hasta 600 quemadores Carcel; i que tomando como base de cálculo, medio quilográmetro por quemador, los resultados son mas que aproximados. Estos datos se han obtenido despues de numerosos trabajos hechos en Francia i en el estranjero.

Otra de las cuestiones que es necesario estudiar tratando de la planteacion del alumbrado eléctrico, es averiguar el precio o costo de ese alumbrado. Con ese objeto damos a continuacion un resúmen que nos muestra el costro del alumbrado en Paris, realizado con los diversos procedimientos i produciendo igual intensidad luminosa.

CEADRo comparativo del precic de diversos alunbrados.

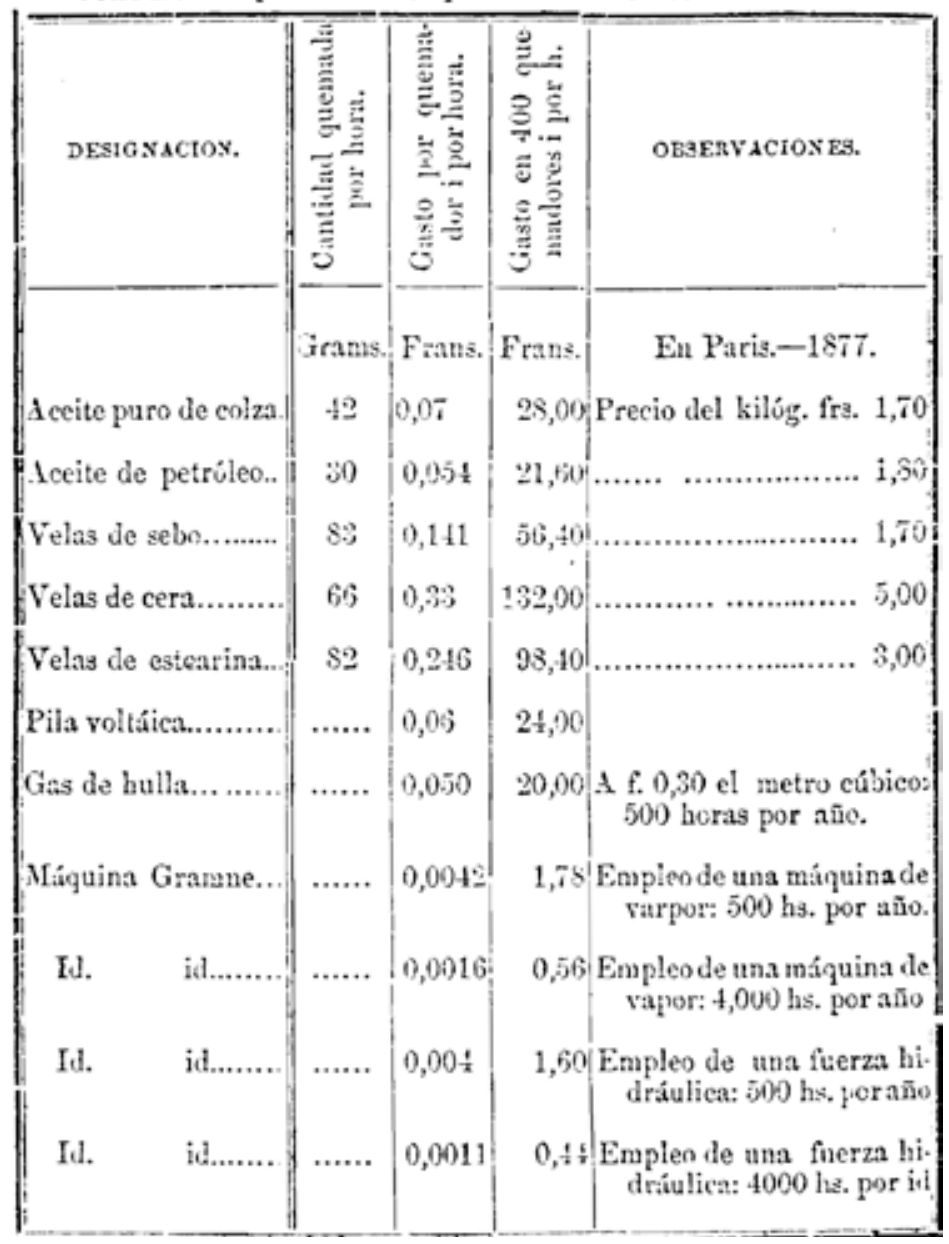


Este cuadro nos hace ver a primera vista que el alumbrado eléctrico es ventajoso. Sin embargo, los gastos de instalacion son considerables, i los resultados consignados deben ser un tanto modificados si se atiende a que hai cierta tendencia a deprimir los demas alumbrados, para hacer sobresalir las cualidades del alumbrado eléctrico. De estudios mui sérios hechos en Paris, se desprende no obstante, que a igual emision de luz, la eléctrica cuesta ménos que el gas; i tomando en consideracion el interés del dinero invertido i uso del material, los costos de uno i otro alumbrado se encuentran en la proporcion de 1 a 2,26. Entre nosotros es necesario agregar, que la diferencia seria mayor. Así, aunque la instalacion de los aparatos eléctricos seria mas dispendiosa i el interés del dinero es mas subido, en cambio el gas tiene un precio excesivamente alto comparado con el de Paris.

Damos en seguida las reglas prácticas que es necesario observar para sacar todo el partido posible de los aparatos, sin que sufran deterioros ni interrupciones.

1. Instalacion de la máquina.- Debe colocarse donde no haya limaduras metálicas, sobre un zócalo ríjido de cualquier material, cuidando que los piés reposen bien i queden fácilmente asequibles los diferentes órganos.

Los hilos de cobre que conduzcan la electricidad de las máquinas a los reguladores, deben tener un diámetro tanto mayor cuando mayor sea su lonjitud: para 5 metros de distancia entre la máquina i el regulador, los hilos conductores deben tener $1 \mathrm{~mm}$. de diámetro; de 5 a 10 metros, 11/2 mm.; de 10 a 20 metros, $2 \mathrm{~mm}$. i en jeneral el diámetro que indique la teoría. Pasando la distancia de 110 metros es necesario cambiar la velocidad de la máquina, colocándose en circunstancias teóricas mui distintas; por consiguiente, no convendrá pasar de 50 metros de distancia entre la máquina i el regulador sí se quiere tener el mayor efecto útil.

2. Aislamiento de los conductores.- Si los hilos no están cubiertos de una materia aisladora de la electricidad, no deben tocarse ni estar en contacto con la tierra en ninguno de los puntos de su trayecto. Los puntos de suspension deben estar bien aislados.

3. Velocidad i sentido del movimiento.- La velocidad puede variar de 850 a 900 vueltas por minuto; pero una vez obtenida debe mantenérsela constante durante toda la marcha. Se mide fácilmente la velocidad empleando un contador velocimetro de Deschiens, que basta aplicar en el eje de la máquina durante un tiempo determinado.

Las máquinas Gramme pueden funcionar en tension o en cantidad. Para obtener estos resultados diferentes basta cambiar la velocidad.

La intensidad I de una corriente producida por $n$ elementos de una pila nos es dada por la fórmula mui conocida en física, en que $\mathrm{E}$ i $\mathrm{R}$ representan la fuerza electro-motriz i la resistencia de cada elemento, i $r$ la resistencia del conductor.

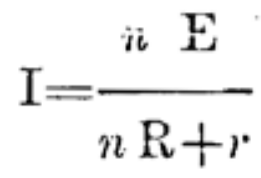


Esta fórmula jeneral encierra la solucion de todas las cuestiones que se presentan empleando la pila; permite prever para cada disposicion adoptada, la intensidad de la corriente que recorrerá un circuito cerrado. Así, se observa que haciendo variar a $\mathrm{R}$, obtendremos variaciones correspondientes para la intensidad; por consiguiente será mui sencillo cambiando el arreglo de los elementos en una batería, aumentar o disminuir la resistencia i por consiguiente tener una pila armada en tension o en cantidad. ${ }^{11}$ Puesto que a $\mathrm{R}$ la podemos hacer variar a voluntad, el arreglo conveniente en un caso dado dependerá de $r$.

I es esto precisamente lo que pasa con la máquina de Gramme; se ha observado por ejemplo, que a una máquina que necesita cuatro caballos de fuerza para obtener 600 vueltas por minuto i producir una intensidad luminosa equivalente a 1200 quemadores, se la puede hacer producir 2500 quemadores con una velocidad de 1200 vueltas i absorviendo ocho caballos.

M. Mascart fue el primero que hizo ver esa proporcionalidad entre la tension i la velocidad de rotacion en los aparatos de Gramme, i de ahí se dedujo la posibilidad de emplear esta máquina para la medida de las fuerzas electromotrices, siguiendo los métodos que enseña la física.

De esta manera que si una vez obtenida la luz de una intensidad dada, queremos alejarnos con el regulador, del manantial de electricidad sin que cambie esa intensidad, no tendremos sino que aumentar el número de revoluciones por minuto, cuidando naturalmente de no pasar de cierto límite, que depende de la conservación de los aparatos i gasto que se orijina desarrollando una fuerza mayor que la normal. Es también necesario tomar la precaucion de que la correa va del volante al tambor esté siempre convenientemente tendida, porque los resbalamientos sobre la polea dan lugar a irregularidades en la luz.

La bobina de la máquina debe jirar en el sentido determinado por la posicion de las escobillas. Estas deben mantenerse con sus alambres bien lisos i rectos.

4. Escobillas.- Deben ejercer una débil presion sobre el cilindro. Se las arreglará con suavidad, hasta que froten lijeramente sin que produzcan chispas. Si la presion fuera considerable se produce un rápido desgastamiento; si mui débil, se producen chispas que gastan igualmente las piezas con las cuales están en contacto. No hai inconveniente en que produzcan chispas pequeñas.

Revísense frecuentemente las escobillas i límpieselas con alcohol. Si los alambres se sueldan, no hai sino gastar la escobilla en un molejon de diámetro mas pequeño que el cilindro en el cual frota la escobilla, hasta gastar completamente la parte soldada.

11. Se dice que los elementos de una pila están asociados en cantidad, cuando todos comunican por sus polos del mismo nombre. En este caso la fuerza electro-motriz de la pila es débil; es igual a la de un solo elemento. De esta manera se obtiene una cantidad mui considerable de electricidad que circula con una débil tension.

Cuando los elementos, por el contrario, están dispuestos en séries paralelas formando batería, unidos los polos de nombre contrario, se tiene una asociacion en tension. 
Es necesario tomar la precaucion de apretar los contra-rejistros de los tornillos de arreglo, con el objeto de que los porta-escobillas no se suelten con las vibraciones de la máquina.

5. Engrasado de los cojinetes.- Deben estar los cojinetes del eje de la bobina constantemente engrasados, lo que se consigue siempre que los vasos contienen aceite i que sus vástagos funcionan. Si se calentarán los cojinetes, deben sacarse los vasos e introducir un poco de flor de azufre en los agujeros en que se colocan.

6. Caldeo de la máquina.- Puede ésta calentarse sin inconveniente mientras pueda tenerse la mano sobre los hilos del electro-iman superior. El calentamiento máximum se obtiene despues de algunas horas de marcha. Si se sobreasa la temperatura estrema, será necesario disminuir la velocidad de réjimen de la máquina.

7. Lámpara eléctrica. - Es necesario tener siempre mui limpio el vástago motriz asi como el tubo ascendente del porta-carbon inferior. Esto se consigue con el papel de esmeril mui fino.

Para colocar los carbones es necesario hacer jirar sobre sí misma la pieza rotatoria del porta-carbon inferior, de manera que encaje la clavija de cobre en el soporte de marfil, i tirar en seguida de abajo hácia arriba el porta-carbon superior. Deben escojerse, en cuanto sea posible, carbones de la misma contextura, colocando el mas largo en la parte superior.

Los carbones deben quedar bien apretados i enfrente uno de otro; en seguida se pone en libertad la pieza rotatoria para dejar que los carbones queden en contacto. Si no se efectuase el movimiento de los porta-carbones, seria necesario mover el tornillo colocado detrás del aparato, i que ya hemos descrito detenidamente, haciéndolo jirar en el sentido de la flecha $\mathrm{R}$, hasta que los carbones se acerquen automáticamente.

8. Arreglo del arco voltáico.- Funcionando convenientemente, es necesario que el arco voltáico se mantenga entre 0,m003 i 0,m004.

Haciendo jirar el tornillo en el sentido de la flecha R, se disminuye la dimension del arco; i por el contrario, haciéndolo jirar en el sentido de la flecha E, se aumenta la dimension del arco.

La lámpara, en jeneral, queda bien arreglada cuando el tornillo está a 3/4 de vuelta en el sentido de $\mathrm{R}$, una vez que se ha percibido el sonido de los engranajes en el interior de la lámpara.

9. Manera de funcionar de los aparatos.- Cuando todo está arreglado, las máquinas tienen la velocidad conveniente: motor de vapor i magneto-eléctrica; las escobillas convenientemente apretadas, i las lámparas prontas para funcionar, se establece la comunicación entre las lámparas i las máquinas por medio de un conmutador.

Si los carbones se encendiesen con dificultad, eso probaría que el tornillo de arreglo estaba mui apretado o los carbones mui juntos. En ese caso la fuerza motriz debe ser mayor, i en este momento es de todo punto necesario impedir el resbalamiento de la correa en las poleas. 
Despues de algunos minutos de marcha es necesario asegurarse de que el carbon superior se talla en hueco i el inferior en punta. Si se produjera lo contrario, seria necesario detener la lámpara i cambiar la posicion de los hilos en los polos de la máquina.

$10^{\circ}$. Cambio de carbones.- Tener cuidado de detener la máquina cuando los carbones estén casi consumidos; de otra manera se quemarían los porta-carbones.

$11^{\circ}$. Motor.- Se emplea casi esclusivamente el de Brotherhood con tres cilindros. Su regularidad en el movimiento, pequeñas dimensiones i poco consumo de combustible, lo hacen uno de los mas apropiados en estas clases de instalaciones. Entrar en mas detalles a este respecto, seria extralimitar el plan que nos hemos impuesto. Por otra parte, con los datos que hemos dado acerca del trabajo consumido i velocidad requerida, será siempre fácil encontrar el motor apropiado.

\section{APLICACIONES INDUSTRIALES DEL ALUMBRADO ELÉCTRICO}

No somos de aquellos que creen que ha llegado para la luz eléctrica el dia de su aplicación en todos los casos, i que los demas sistemas de alumbrado están llamados a desaparecer en un tiempo mas o ménos corto. La subdivisión de la luz eléctrica de tal manera que puedan emplearse lámparas que equivalgan a un corto número de quemadores, la regularidad en su manera de funcionar, el poco costo i otras condiciones que reúne el alumbrado de gas de hulla, i que todavía i a pesar de los grandes progresos realizados en los cinco últimos años, no posee el alumbrado eléctrico, son tropiezos que quedan por vencer en la aplicación práctica de este problema científico.

Con todo, el alumbrado eléctrico es empleado en gran número de casos ventajosamente, cuando ello se orijina de la naturaleza misma de la luz. La intensidad de la luz eléctrica permite su difusion reflejada por todos los objetos que hiere, tal como sucede con la luz del sol; no siendo el resultado de una combustion, no priva al aire de su oxíjeno, i de aquí sus propiedades hijiénicas. De la facilidad de producir la luz eléctrica donde quiera que haya un motor, nace su aplicación en las faenas agrícolas, utilizando sus motores i haciendo posible continuar los trabajos en épocas en que es necesario proceder con rapidez.

Pero una de sus propiedades mas notables, es la semejanza de la luz eléctrica en los caracteres espectrales con la luz del sol, haciéndola por esta razón, aplicable a los procedimientos fotográficos, i a ciertos delicados trabajos industriales i artísticos que exijen una relación definida en el colorido. Efectivamente, todo el mundo ha podido observar que la luz de los quemadores de gas parece de un color amarillo anaranjado cuando se les enciende ántes de anochecer, i lo mismo sucede cuando se la compara con la luz eléctrica. El ojo es un órgano tan complaciente, i de tal manera nos hemos habituado al color amarillento del gas, que no solamente no lo notamos, sino que acusamos a la luz eléctrica de ser demasiado brillante i parecerse a la del dia. Esta cuestión merece ser un tanto desarrollada, a pesar de que haciéndolo, entramos en nuevos detalles. 
Se sabe desde la época de Newton, que la luz emitida por los diferentes focos es compleja; siempre está compuesta de una mezcla de rayos que se llaman simples, que un prisma tiene la propiedad de separar, hacer visibles i ordenar según sus desviaciones desiguales, en una imájen alargada que se llama espectro. Esos rayos afectan diferentemente el ojo; sus tintas se continúan por graduaciones insensibles, harmoniosas, pasando por siete tipos principales que son el rojo, el anaranjado, el amarillo, el verde, el azul, el índigo i el violeta. Esos colores simples son los elementos de todas las tintas posibles i también de los rayos luminosos emitidos por todas las luminarias posibles. Pero es menester que esas luminarias contengan a todos esos colores i en igual proporcion. Por ejemplo, el arco eléctrico que se produce entre un metal como la plata i un carbon, no contiene sino dos bandas verdes, i si se reemplaza la plata por otros metales, el espectro que se obtiene está siempre formado por rayas brillantes separadas por anchos espacios oscuros.

Por consiguiente, esas luces son mui incompletas i en ningún caso podrán servir para el alumbrado.

Pero las llamas del aceite o del gas se resuelven, por el contrario, en un espectro contínuo; el rojo, el anaranjado i el amarillo son mui abundantes; hai poco verde, casi nada de azul i nada de violeta. Esas llamas son, por consiguiente, ricas en colores poco refranjibles, i es eso lo que les dá el tinte anaranjado.

La luz eléctrica es mas compleja; proviene a la vez de los carbones i del arco, i difiere según uno u otro de esos dos oríjenes. La que proviene de los carbones es blanca; es absolutamente la misma que la luz del sol i contiene todos los rayos simples en las mismas proporciones. Es completa i perfecta, reemplaza, en una palabra, a la luz del día. No sucede lo mismo con la que envía el arco voltáico, que es azul violeta i su espectro, inverso del de las lámparas de aceite o gas; contiene poco rojo, mucho azul i un exceso de violeta. De aquí proviene el que la luz eléctrica tenga un viso azulado mui perceptible. Pero si es imposible dar a las lámparas los colores que les hacen falta, sucede que podemos quitar a la luz eléctrica los colores que tiene un exceso, empleando procedimientos mui sencillos i que no es del caso esponer aquí. De ahí la verdadera superioridad de la luz eléctrica, a que hemos aludido anteriormente.

En jeneral, las dos cuestiones que a nuestro juicio deben examinarse al plantear un alumbrado cualquiera, son: su precio de costo i la comodidad de su empleo. El primer punto podrá resolverse aproximadamente, teniendo presente que, los aparatos necesarios para iluminar completamente un espacio de 500 metros cuadrados, importan en Francia 2,400 francos.

En Francia, Inglaterra i otros países, existen actualmente numerosos establecimientos que tienen sus talleres i patios alumbrados con luz eléctrica; las ventajas de continuar el trabajo durante la noche en condiciones análogas al del dia, compensan el costo de instalacion i mantenimiento de este nuevo alumbrado. Pero la luz eléctrica es de una importancia insuperable en los faros, en las naves i en las operaciones militares; puntos que tocaremos a la lijera. 


\section{ALUMBRADO EN LOS FAROS}

En 1863 se estableció por primera vez la luz eléctrica en el faro de primer órden de la Heve cerca del Havre, con una máquina magneto-eléctrica de la «Alianza» i los resultados fueron del todo satisfactorios.

El interesante informe de M. Quinette de Rochemont, injeniero comisionado por el gobierno francés para estudiar los resultados obtenidos con el empleo de la luz eléctrica en los faros, dice lo siguiente: «Desde hace seis años, época en que la luz eléctrica fue instalada por primera en la Heve, hasta la fecha, ha trascurrido suficiente tiempo para apreciar con exactitud el valor de aquel jénero de alumbrado bajo el punto de vista de su empelo en las costas.

«Los navegantes se complacen en reconocer los servicios prestados por los faros eléctricos; las ventajas del sistema han sido vivamente apreciadas; el aumento en la intensidad de los destellos es mui sensible, especialmente durante un tiempo brumoso; permite a los buques proseguir su marcha i entrar a los puertos durante la noche i en condiciones tales que habría sido imposible verificarlo con faros con luz de aceite.

«La luz que al principio dejaba que desear por su movilidad ha llegado a tener una notable fijeza, gracias a los perfeccionamientos de los aparatos i a la experiencia adquirida por los guardianes.

«Los temores que a priori pudieron concebirse con respecto a la delicadeza en el manejo de ciertos aparatos, no se han realizado en la práctica. Los accidentes han sido raros, las extinciones cortas i poco numerosas; dos solamente, durante este período de seis años han sido de alguna duración; la una de una hora, causada por una avería en la máquina de vapor; la otra, de cuatro horas que, según parece, fue funcional. No debe pues, preocupar la cuestión de accidentes posibles.»

Hoi dia existe considerable número de faros eléctricos en Francia, Inglaterra, Rusia, Austria, Suecia i Ejipto. En todas partes funcionan satisfactoriamente; i si la transformación no es total, ello es debido sin duda, a que no es posible desechar un material enorme i que dá excelentes resultados para reemplazarlo por otro mejor. Los nuevos faros que se establezcan o que sea necesario reconstruir serán modificados; i en este caso parece encontrarse nuestro país, que empieza a establecer de una manera científica el alumbrado de sus costas.

\section{ALUMBRADO EN LOS BUQUES}

La luz eléctrica aplicada a la navegación tiene por objeto, principalmente, aumentar la seguridad de los viajes, evitando los abordajes i facilitando la entrada a los puertos. Permite operar la carga i descarga i maniobras de todo jénero en una noche sombria tan bien como en pleno dia i sin riesgos de incendios.

La sencillez de los aparatos Gramme, su poco peso i la regularidad de su acción, los hace mui adecuados para la marina. 
En la mayor parte de las naves de la armada francesa se han instalado aparatos Gramme; el blindado «Victorieuse», por ejemplo, está dotado de una máquina de 2000 quemadores Carcel que proyecta con un reflector conveniente, un haz de luz que a 4000 i mas metros de distancia, permite distinguir costas, buques, casas, balizas, hombres, etc. Estos aparatos sirven, además, para establecer correspondencia telegráfica, ya por destellos de luz de un punto de observación a otro, ya por refleccion sobre objetos intermedios visibles a la vez de ámbas estaciones, cuando éstas no pueden comunicar directamente, tales como un tramo de costa, una nube, etc.

Se pueden arreglar a bordo de un buque varias lámparas eléctricas, abastecidas todas ellas por una sola máquina; i hacer pasar los conductores por la cámara del comandante, quien teniendo a la mano los conmutadores, es dueño de hacer nacer o interrumpir la luz en cada una de las lámparas, simultánea o alternativamente, o producir destellos sin que se detenga el movimiento de la máquina jeneradora.

\section{APLICACIONES MILITARES}

En las operaciones de guerra tiene la luz eléctrica aplicaciones análogas a las indicadas para las naves; i especialmente para la defensa de las plazas fuertes i telégrafo óptico en reemplazo del heliógrafo o telégrafo con destellos solares.

La máquina indicada en la Figura 8 es el modelo que la mayor parte de las naciones europeas han adoptado para utilizarla en los ejércitos. Ella posee las cualidades de lijereza i potencias necesarias.

Para las señales del telégrafo óptico, M. Gramme ha construido una máquina de pequeñas dimensiones que se pone en movimiento a brazo. Cuatro hombres la hacen producir una luz equivalente a 50 quemadores Carcel. Para facilitad su transporte se la instala en un carro.

En vista de los hechos que hemos consignado a la lijera, séanos permitido espresar el deseo de que nuestro Gobierno dote a nuestra armada i faros de la dilatada costa de Chile, de los aparatos Gramme que tan buenos resultados dan en todas partes.

Nos es grato dejar constancia que ya el Ministerio de Marina a puesto a disposición del jefe de la escuadra, una máquina Gramme de pequeñas dimensiones, que puede prestar algunos servicios i a cuya instalacion i manejo están destinados estos lijeros apuntes.

Creo un deber espresar con esta ocasión, los servicios prestados por el señor L. Chapron, jefe de los trabajos del muelle fiscal de Valparaiso, al proporcionar todos los elementos de que disponía, para el ensayo i estudio de la primera máquina de Gramme, destinada al alumbrado eléctrico, llegada al país. 